\title{
(2) PAX-D: study protocol for a randomised placebo- controlled trial evaluating the efficacy and mechanism of pramipexole as add-on treatment for people with treatment resistant depression
}

\author{
Sheena Kristine Au-Yeung (ㅇ, , James Griffiths, ${ }^{1}$ Sophie Roberts, ${ }^{1}$ Chloe Edwards, ${ }^{1}$ \\ Ly-Mee Yu, ${ }^{2}$ Rafal Bogacz, ${ }^{3}$ Jennifer Rendell, ${ }^{1,4}$ Mary-Jane Attenburrow (1) 1,4 \\ Stuart Watson, ${ }^{5,6}$ Fiona Chan, ${ }^{7}$ Andrea Cipriani ${ }^{10},{ }^{1,4}$ Anthony Cleare, ${ }^{8}$ \\ Catherine J Harmer, ${ }_{1}^{1}$ David Kessler, ${ }^{9}$ Jonathan Evans,${ }^{9}$ Glyn Lewis, $^{10}{ }^{1 \text { lina Singh, }}{ }^{1}$ \\ Judit Simon (1) , ${ }^{11}$ Paul J Harrison, ${ }^{1,4}$ Phil Cowen, ${ }^{1,4}$ Milensu Shanyinde, ${ }^{2}$ \\ John Geddes, ${ }^{1,4}$ Michael Browning ${ }^{1,4}$
}

- Additional supplemental material is published online only. To view, please visit the journal online (http://dx.doi. org/10.1136/ebmental-2021300282).

For numbered affiliations see end of article.

\section{Correspondence to} Dr Sheena Kristine Au-Yeung, University of Oxford Department of Psychiatry, Oxford, Oxfordshire, UK; SAuYeung1@ sheffield.ac.uk
Check for updates

(C) Author(s) (or their employer(s)) 2021. Re-use permitted under CC BY. Published by BMJ.

To cite: Au-Yeung SK, Griffiths J, Roberts S, et al. Evid Based Ment Health Epub ahead of print: [please include Day Month Year]. doi:10.1136/

ebmental-2021-300282

\section{ABSTRACT}

Introduction Clinical depression is usually treated in primary care with psychological therapies and antidepressant medication. However, when patients do not respond to at least two or more antidepressants within a depressive episode, they are considered to have treatment resistant depression (TRD). Previous small randomised controlled trials suggested that pramipexole, a dopamine D2/3 receptor agonist, may be effective for treating patients with unipolar and bipolar depression as it is known to influence motivational drive and reward processing. PAX-D will compare the effects of pramipexole vs placebo when added to current antidepressant medication for people with TRD. Additionally, PAX-D will investigate the mechanistic effect of pramipexole on reward sensitivity using a probabilistic decision-making task.

Methods and analysis PAX-D will assess effectiveness in the short- term (during the first 12 weeks) and in the longer-term (48 weeks) in patients with TRD from the UK. The primary outcome will be change in selfreported depressive symptoms from baseline to week 12 post-randomisation measured using the Quick Inventory of Depressive Symptomatology Self-Report (QIDS-SR16). Performance on the decision-making task will be measured at week 0 , week 2 and week 12. Secondary outcomes include anhedonia, anxiety and health economic measures including quality of life, capability, well-being and costs. PAX-D will also assess the adverse effects of pramipexole including impulse control difficulties.

Discussion Pramipexole is a promising augmentation agent for TRD and may be a useful addition to existing treatment regimes. PAX-D will assess its effectiveness and test for a potential mechanism of action in patients with TRD.

Trial registration number ISRCTN84666271

\section{INTRODUCTION}

When patients do not respond to at least two or more antidepressants within a depressive episode, they are considered to have treatment resistant depression (TRD). This accounts for roughly $20 \%-30 \%$ of all depressed patients and is a leading cause of morbidity and workdays lost. Currently there is a shortage of effective pharmacological options for patients who fall within this category. ${ }^{1}$

The large, pragmatic Sequenced Treatment Alternatives to Relieve Depression (STAR*D) trial suggested that the chances of remission with conventional pharmacological approaches for patients with TRD are less than $15 \%{ }^{2}$ A systematic review $^{3}$ indicated that the best, current, evidencebased treatment is addition of atypical antipsychotic medications such as aripiprazole or quetiapine. However, these agents are only moderately effective and have high dropout rates associated with adverse effects. The extent and frequency of these adverse effects (sedation, weight gain and movement disorders) mean that this 'atypical augmentation' is widely disliked by patients. Another option is adding lithium to an antidepressant, but the evidence base is limited and lithium is poorly tolerated, potentially toxic and again disliked by patients. No new antidepressant is more effective than tricyclic antidepressants which were discovered serendipitously over 60 years ago. The pharmaceutical industry has largely withdrawn from this area because of the difficulty of making real advances.

There is preliminary evidence that the dopamine agonist, pramipexole, could represent an important advance in TRD. A systematic review by Tundo et $\mathrm{al}^{4}$ identified five completed randomised controlled trials (RCTs), three open-label trials and five observational studies of pramipexole for patients with major depressive episodes and reported beneficial effects of pramipexole for patients with unipolar and bipolar depression. An RCT by Cusin et $a l^{5}$ with 65 unipolar TRD patients found significant benefit of pramipexole, administered at a relatively low average dose of $1.3 \mathrm{mg} /$ day, over placebo on a continuous outcome symptom measure but not in terms of response ( $40 \%$ vs $27 \%$ ). Another RCT 
by Corrigan $e t a l^{6}$ examining pramipexole monotherapy in nontreatment resistant unipolar depression found that $1 \mathrm{mg}$ was superior to placebo, while $0.375 \mathrm{mg}$ was ineffective and $5 \mathrm{mg}$ caused very high drop out. A very small study by Franco-Chaves et $\mathrm{al}^{7}$ ( $\mathrm{n}=13$ per group) of unipolar patients resistant to a single previous antidepressant randomised to receive pramipexole monotherapy (target dose $=2.25 \mathrm{mg}$ ), pramipexole combined with escitalopram or escitalopram monotherapy, found no statistical difference between the study groups, although only four patients in the combined group completed the study. Two RCTs of bipolar depression by Zarate et $a l^{8}$ and Goldberg et $a l^{9}$ found that patients on pramipexole (average dose of $1.7 \mathrm{mg}$ ) were more likely to have better therapeutic response than those on placebo. A case series of TRD patients treated in the US by Fawcett et $a l^{10}$ reported very good therapeutic responses to pramipexole augmentation of antidepressant therapy in 42 patients with depression at a mean dose of around $2.5 \mathrm{mg} /$ day. However, given the small sample sizes and inconsistent results summarised above, the review by Tundo et $a l^{4}$ concluded that adequately powered RCTs of pramipexole for depression are still needed.

The target dose of pramipexole used in PAX-D will be $2.5 \mathrm{mg} /$ day as a single dose. The target dose was selected to be above the average achieved dose of the Cusin et al study ${ }^{5}$ and between the effective $1 \mathrm{mg} /$ day dose and non-tolerated $5 \mathrm{mg} /$ day dose of the Corrigan et al study, ${ }^{6}$ while keeping within the smPC upper limit of $4.5 \mathrm{mg} /$ day. The dosing schedule, with medication administered once daily rather than in divided doses as in Cusin et al, ${ }^{5}$ followed that reported for participants under 45 years of age in the Fawcett et al case series. ${ }^{10}$

Pramipexole is of particular interest because it is a selective dopamine D2/D3 receptor agonist and therefore pharmacologically distinct from currently available antidepressants which mostly act to increase levels of serotonin in the synapse. Experiences of low motivation and anhedonia are thought to be related to the function of the central dopaminergic system which is not specifically targeted by current medicines. ${ }^{11}$ Dopaminergic signalling is believed to be required when learning about rewarding outcomes. ${ }^{12}$ Previous studies of pramipexole in patients with Parkinson's disease ${ }^{13}$ and bipolar disorder ${ }^{14}$ completing reward learning tasks indicated that it acted to increase reward sensitivity (ie, to cause patients to treat rewarding outcomes as if they were more valuable). This raises the possibility that increased reward sensitivity is a cognitive mechanism by which pramipexole improves symptoms of depression. Pramipexole is also studied in an ongoing trial about TRD in bipolar disorder. ${ }^{15}$

\section{Objectives}

The primary objective of PAX-D is to assess the efficacy of adding pramipexole to conventional antidepressant medication for treating symptoms of depression. Pramipexole will be administered under double-blind, placebo- controlled conditions in patients with TRD. Second, PAX-D will examine the effect of pramipexole on reward sensitivity and whether this may predict treatment outcome. A decision-making task ${ }^{16}$ will be used in the current trial to measure the impact of pramipexole on reward sensitivity. The relationship between pramipexole treatment, change in reward sensitivity and symptomatic response will be formally assessed using a mediation analysis. Further, the trial will estimate the degree to which baseline and initial changes in reward sensitivity are able to predict response to pramipexole, providing a first test of the potential for these measures to be deployed in the selection of treatments for TRD patients. Finally, PAX-D will conduct an economic analysis of pramipexole and its longer-term effect on quality of life, capability, well-being, functioning and costs. Finally, the acceptability and tolerability of pramipexole will be assessed across the course of treatment. All objectives are summarised in table 1 .

\section{METHODS AND ANALYSIS \\ Design}

PAX-D is a multisite, double-blind, placebo-controlled, randomised trial evaluating the effects of the addition of pramipexole to antidepressant treatment in patients with TRD. Participant involvement in the trial will have two phases, a pre-treatment, pre-randomisation, run-in phase and a postrandomisation 48-week treatment phase (see figure 1). The run-in phase will assess potential participants' ability to complete study activities and to mitigate baseline inflation effects on outcome measures. Since there is no widely accepted, first-line treatment for TRD, the comparator in the current trial will be addition of placebo. Participants will be randomised to receive either pramipexole or placebo at the randomisation visit. Participants, investigators and the trial team will remain blind to allocation. Pharmacy staff will be unblinded for dispensing purpose.

\section{Recruitment}

Participants will be recruited from primary and secondary care services associated with the trial sites or by self-referral. The study will be advertised to local clinicians and in local and online media. Following a single-site internal pilot at the Oxford Health National Health Service (NHS) Foundation Trust, recruitment will continue in four additional sites across the UK (Newcastle, Bristol, Kings College London and University College London), and then extended to other NHS mental health trusts in regions around these sites as needed.

\section{Eligibility}

The eligibility criteria are summarised in figure 2. During the study visits, participants will be assessed by a research assistant (RAs) and a psychiatrist.

\section{Interventions}

In the Pramipexole for depression (PAX-D) trial, pramipexole will be added to an antidepressant that the participant is prescribed outside of the trial. The psychiatrist will be responsible for trial medication prescription. Pramipexole tablets will be taken orally. All dosages are reported as pramipexole salt (NB $1 \mathrm{mg}$ of pramipexole salt is equivalent to $0.7 \mathrm{mg}$ of pramipexole base). Pramipexole dihydrochloride monohydrate will be initiated at $0.25 \mathrm{mg} /$ day and, in the absence of concerns about tolerability, the dose will be increased by $0.25 \mathrm{mg} /$ day every 3 days towards a target dose of $2.5 \mathrm{mg} /$ day (see online supplemental material for titration schedule). The target dose was selected to be at the upper end of those used in previous trials ${ }^{6-10}$ as the case series of TRD patients reported by Fawcett et $a l^{10}$ indicated that a number of patients responded to higher doses. The titration schedule was also based on the Fawcett case series. ${ }^{10}$ The titration schedule may be amended at the discretion of the treating psychiatrist. Specifically, participants who are unable to tolerate an increased dose of pramipexole, for example, due to adverse effects, will be advised to reduce the dose to the highest tolerated. Participants will remain on this highest tolerated dose throughout the remainder of the trial. No re-titration will be attempted. Any dose reductions will be tapered every 3 days. This will reduce the risk of developing dopamine agonist withdrawal syndrome. For more information on managing adherence, discontinuing, 
Table 1 Study objectives (from https://www.isrctn.com/ISRCTN84666271)

\begin{tabular}{|c|c|c|}
\hline Objectives & Outcome measures & Time points \\
\hline Primary objective & Primary outcome & \\
\hline $\begin{array}{l}\text { To compare the efficacy of pramipexole and placebo at } 12 \\
\text { weeks postrandomisation }\end{array}$ & Improvement (change from baseline) of depressive symptoms measured on the $\mathrm{QIDS}^{-\mathrm{SR}_{16}}$ & Week 1-12 \\
\hline Secondary objectives & Secondary outcomes & \\
\hline $\begin{array}{l}\text { To compare the tolerability and safety of pramipexole and } \\
\text { placebo during the } 48 \text {-week treatment phase }\end{array}$ & $\begin{array}{l}\text { Tolerability assessed by: } \\
\text { Termination of trial treatment due to intolerance } \\
\text { Adverse reactions } \\
\text { STQM-9 } \\
\text { Safety-emergence of new symptoms: } \\
\text { ALTMAN (manic symptoms) } \\
\text { QUIP-RS (impulse control) } \\
\text { Suicidal ideation (QIDS-SR }{ }_{16} \text { ) }\end{array}$ & Weeks 1-48 \\
\hline $\begin{array}{l}\text { To compare the effect of pramipexole and placebo on reward } \\
\text { sensitivity }\end{array}$ & $\begin{array}{l}\text { Change in reward sensitivity parameter from model fitted to learning/decision making } \\
\text { task between baseline, week } 2 \text { and week } 12\end{array}$ & $\begin{array}{l}\text { Baseline, week 2, } \\
\text { week } 12\end{array}$ \\
\hline $\begin{array}{l}\text { To test the degree to which change in reward sensitivity } \\
\text { mediates the } 12 \text { weeks response to pramipexole of both } \\
\text { depressive, and specifically anhedonic, symptoms }\end{array}$ & $\begin{array}{l}\text { Change in QIDS-SR }{ }_{16} \text { and SHAPS scores between baseline and week } 12 \text { and change in } \\
\text { reward sensitivity between baseline and week } 2\end{array}$ & $\begin{array}{l}\text { Baseline, week 2, } \\
\text { week } 12\end{array}$ \\
\hline $\begin{array}{l}\text { To compare the extent to which an increase in reward } \\
\text { sensitivity predicts therapeutic response }\end{array}$ & $\begin{array}{l}\text { Change scores in the learning/decision making task at } 2 \text { weeks and the change in the } \\
\text { QID-SR }_{16} \text { at } 12 \text { weeks }\end{array}$ & Week 2, week 12 \\
\hline $\begin{array}{l}\text { To explore the extent to which reward sensitivity at baseline } \\
\text { predicts therapeutic response }\end{array}$ & $\begin{array}{l}\text { Baseline scores on the learning/decision making task and the change in QIDS-SR }{ }_{16} \text { at } 12 \\
\text { weeks }\end{array}$ & Baseline, week 12 \\
\hline $\begin{array}{l}\text { To explore the extent to which level of anhedonia at baseline } \\
\text { predicts therapeutic response }\end{array}$ & Baseline scores on SHAPS and change in the QIDS-SR ${ }_{16}$ at 12 weeks & Baseline, week 12 \\
\hline $\begin{array}{l}\text { To compare the effect of pramipexole and placebo on the } \\
\text { trajectory of symptoms of depression }\end{array}$ & QIDS-SR $_{16}$ scores collected weekly across 48 weeks of the trial & Weekly for week 1-48 \\
\hline $\begin{array}{l}\text { To compare the effect of pramipexole and placebo on } \\
\text { response and remission rates, using the QIDS-SR }{ }_{16} \text { at twelve } \\
\text { weeks }\end{array}$ & $\begin{array}{l}\text { QIDS-SR }_{16} \text { response, defined as a reduction of }<50 \% \text { of baseline scores at week } 12 \text {, } \\
\text { remission as a score of }<5 \text { at week } 12\end{array}$ & Baseline, week 12 \\
\hline $\begin{array}{l}\text { To compare the impact of pramipexole and placebo on } \\
\text { symptoms of anhedonia, anxiety and clinician rated } \\
\text { depression }\end{array}$ & Change scores for the SHAPS, GAD-7 and QIDS-C between baseline and week 12 & Baseline, week 12 \\
\hline $\begin{array}{l}\text { To compare the impact of pramipexole and placebo on } \\
\text { functional outcome over the } 48 \text { weeks of treatment }\end{array}$ & Change scores for the WSAS-screener between baseline and week 48 & $\begin{array}{l}\text { Baseline, weeks 12, 24, } \\
36 \text { and } 48\end{array}$ \\
\hline $\begin{array}{l}\text { To determine the impact on quality of life and capability well- } \\
\text { being of pramipexole relative to placebo over } 48 \text { weeks }\end{array}$ & $\begin{array}{l}\text { Change in the following over } 48 \text { weeks: } \\
\text { EQ-5D-5L } \\
\text { ICECAP-A } \\
\text { OxCAP-MH }\end{array}$ & $\begin{array}{l}\text { Baseline, weeks 12, 24, } \\
36 \text { and } 48\end{array}$ \\
\hline $\begin{array}{l}\text { To examine the health/social care and broader societal costs } \\
\text { of patients relative to placebo over } 48 \text { weeks }\end{array}$ & $\begin{array}{l}\text { Change in the following over } 48 \text { weeks: } \\
\text { HEQ }\end{array}$ & $\begin{array}{l}\text { Baseline, weeks 12, 24, } \\
36 \text { and } 48\end{array}$ \\
\hline
\end{tabular}

GAD-7, General Anxiety Disorder Scale; HEQ, Health Economics Questionnaire; ICECAP-A, ICEpop capability measure for adults; OxCAP-MH, Oxford CAPabilities questionnaireMental Health; QIDS-SR16, quick inventory of depressive symptomatology self-report 16; QUIP-RS, Questionnaire for Impulsive-Compulsive Disorders in Parkinson's DiseaseRating Scale; SHAPS, Snaith-Hamilton Pleasure scale; TSQM-9, Treatment Satisfaction Questionnaire for Medication Version 9; WSAS, Work and Social Adjustment Scale.

modifying allocated interventions and concomitant treatments (see online supplemental material).

\section{Assignment of intervention}

Each participant will be randomised at a ratio of $1: 1$ to either pramipexole or a matched placebo. A non-deterministic algorithm will be used to produce treatment groups balanced for important prognostic factors by minimising separately on four variables including (1) trial site, (2) age $(18-50$, vs $>50)$, (3) gender $(\mathrm{M} / \mathrm{F})$ and (4) baseline quick inventory of depressive symptomatology self-report 16 (QIDS-SR16) severity (11-15 vs $16-20$ vs $>20$ ).

\section{Outcomes}

Questionnaires will be administered through a combination of participant self-reports, semi-structured interviews and completion by a psychiatrist during a clinic visit. Participants will complete questionnaires electronically using True Colours, an online platform accessed using electronic devices. ${ }^{17}$ Participants will be telephone contacted by an RA at screening, weekly from week 0 to 12 , then 4 -weekly up to week 48 to complete semistructured interviews asking about adverse effects including any increase in impulsive behaviour or suicidality, any changes in medication and any problems with adherence.

\section{Decision-making task}

The task ${ }^{16}$ consists of 3 runs of 60 trials each (180 trials in total). On each trial, participants are presented with two abstract shapes (letters selected from the Agathodaimon font) and choose the shape which they believe will result in the best outcome. Two shapes are presented during 'win trials' and may result in winning either 20 or 0 points (with one shape leading to a win of 20 points on $70 \%$ of trials and the other shape on $30 \%$ of trials). A separate pair of shapes are associated with 'loss trials' and may result in losing 20 or 0 points (with one shape leading to a loss of 20 points on $70 \%$ of trials and the other shape leading to a loss on $30 \%$ of trials). The shapes used change in each run of the task. Participants must learn from the outcome of previous trials what they think the best shape to choose is. An increased reward sensitivity may cause participants to more consistently 


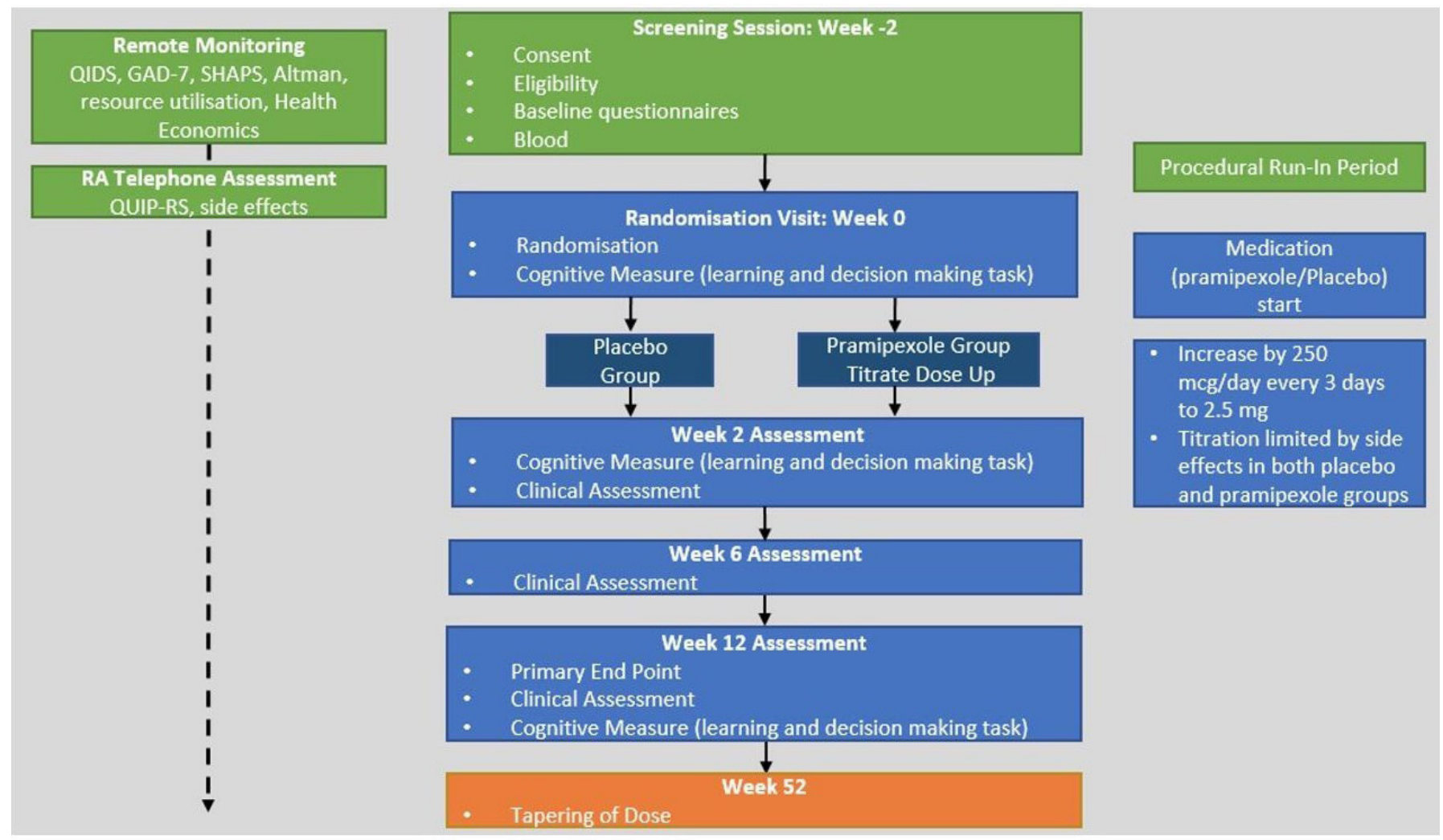

Figure 1 Participant timeline. GAD-7, General Anxiety Disorder Scale 7; RA, research assistant; SHAPS, Snaith-Hamilton Pleasure Scale; QIDS, quick inventory of depressive symptomatology; QUIP-RS, Questionnaire for Impulsive-Compulsive Disorders in Parkinson's Disease-Rating Scale.

select the high probability rewarding outcome in the last half of each block, and is estimated by fitting a standard reinforcement learning model with free parameters for learning rates and outcome sensitivity to participant choices during the win trials. Participants will complete the task via True Colours on a computer during study visits at screening (practice), week 0 (Randomisation), week 2 and 12.

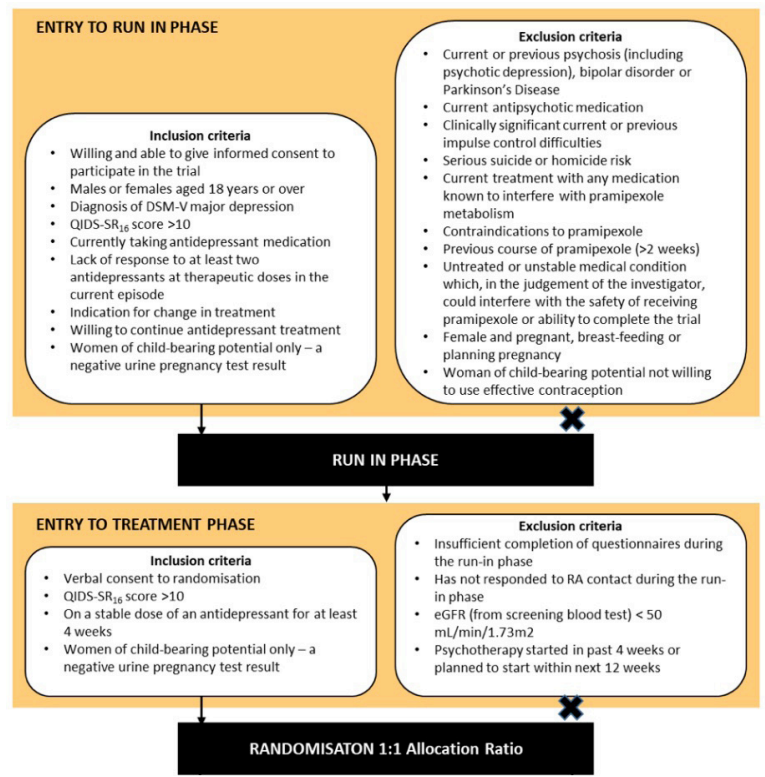

Figure 2 Eligibility criteria. RA, research assistant; QIDS-SR16, quick inventory of depressive symptomatology self-report.
QIDS-SR16 and clinician-rated (QIDS-C)

This is a 16-item questionnaire that covers 9 symptoms of depression. ${ }^{18}$ The scale assesses severity of depression and change in depressive symptoms over time. Participants are instructed to score each item according to the description that best describes their experience over the past 7 days. Each of the symptoms is scored on a 4-point scale (0-3) giving a maximum possible score of 27 (not all items contribute to the total). The total score will detect change in depression symptom-severity, while item 12 will additionally act to detect suicidal thoughts. Clinicians will complete QIDS-C during all study visits. Meanwhile, participants will complete QIDS-SR16 on True Colours once per week from screening to Week 12 , and then once every 4 weeks up to week 48 .

\section{Altman Self-Rating Mania Scale (ALTMAN)}

This is a 5 -item self-report questionnaire that assesses any change in the severity of symptoms of mania. ${ }^{19}$ Participants are instructed to score each item according to the description that best describes how they have been over the past 7 days. Each of the symptoms is scored on a 5-point scale (0-4) giving a maximum score of 20. Participant will complete ALTMAN on True Colours at screening, weekly from randomisation to week 12 , and then 4-weekly up to week 48 .

\section{General Anxiety Disorder Scale-7}

This seven-item self-report questionnaire screens for symptoms of anxiety and measures severity. ${ }^{20}$ Assessment is derived from the total score across all seven items. Participant will complete this on True Colours at screening, weekly from randomisation to week 12, and then 4 weekly up to week 48 . 


\section{Snaith-Hamilton Pleasure Scale}

This is a 14-item scale that measures anhedonia, the inability to experience pleasure. ${ }^{21}$ The items cover the domains of: social interaction, food and drink, sensory experience and interest/ pastimes. Each item has four possible responses: strongly disagree, disagree, agree or strongly agree. Either of the 'disagree' responses score 1 point, and either of the 'agree' responses score 0 points. The final score ranges from 0 to 14 , with higher scores indicating higher levels of anhedonia. Participant will complete this on True Colours at screening, 2-weekly from randomisation to week 12 , and then 4 -weekly up to week 48 .

\section{UCLA Loneliness Scale}

This questionnaire comprises three questions that measure three dimensions of loneliness: relational connectedness, social connectedness and self-perceived isolation. ${ }^{22}$ The scale uses three response categories: 'Hardly ever' (scoring 3)/'some of the time' (scoring 2) /'often' (scoring 1). The scores are added together to give a total score (3 to 9). Participants will complete this scale on True Colours at week 0, 6, 12 and 48.

\section{English Longitudinal Study of Ageing social isolation measure}

This measure is derived from the English Longitudinal Study of Ageing, a nationally representative panel study of people aged 50 years or older living in England. ${ }^{23}$ It is a widely used measure of social isolation, often employed with some modifications. In PAX-D, the whole scale will be collected for the baseline measure, then for weeks 6,12 and 48 the first three response options will be collected ( $3+$ times per week, 1-2 per week, 1-2 per month) with a change of the fourth response to 'not in the past month'. Participants will complete this measure on True Colours at week $0,6,12,48$.

\section{Treatment Satisfaction Questionnaire for Medication Version 9}

The 9-item Treatment Satisfaction Questionnaire for Medication $(\text { TSQM })^{24}$ assesses patient-reported satisfaction of their medication. The domains covered are convenience, effectiveness and global satisfaction. Each item is rated on a seven or five-point scale. TSQM-9 will be completed during RA telephone contact at week $0,6,12,24$ and 48 .

\section{Questionnaire for Impulsive-Compulsive Disorders in Parkinson's Disease-Rating Scale}

The Questionnaire for Impulsive-Compulsive Disorders in Parkinson's Disease-Rating Scale (QUIP-RS) ${ }^{25}$ has four primary questions (pertaining to commonly reported thoughts, urges/ desires, and behaviours associated with impulse control disorders), each applied to the four impulse control disorders (compulsive gambling, buying, eating, and sexual behaviour) and three related disorders (medication use, spending and hobbyism). It uses a 5 -point Likert scale (score $0-4$ for each question) to gauge the frequency of behaviours. QUIP-RS will be completed at screening and then during RA contact weekly from week 0 to 12, then 4-weekly up to week 48.

\section{Work and Social Adjustment Scale}

This measures the impact of a respondent's mental health difficulties on their ability to function in terms of five dimensions (work, home management, social leisure, private leisure and personal or family relationships). ${ }^{26}$ Severity is measured on an eight-point Likert scale (ranging from 'not at all' to 'very severely'. The total Work and Social Adjustment Scale (WSAS) score is derived by adding the scores across all the items. Participants will complete
WSAS on True Colours 4-weekly from week 0 to week 12 , then at week 24,36 , and 48 .

\section{EQ-5D-5L}

This is a standardised measure of health status and provides a generic measure of health-related quality of life for clinical and economic appraisal (https://euroqol.org/eq-5d-instruments/eq5d-5l-about/). The scale has five dimensions (mobility, self-care, usual activities, pain/discomfort and anxiety/depression) and five levels for each dimension (no problems, slight problems, moderate problems, severe problems, extreme problems. A visual scale records the respondent's self-rated health with endpoints labelled 'the best health you can imagine' and 'the worst health you can imagine'. Participants will complete EQ-5D-5L on True Colours at week 0, 12, 24, 36 and 48 .

\section{ICEpop CAPability measure for Adults}

This is a measure of capability for the adult $(18+)$ population for use in economic evaluation. ${ }^{27}$ The measure covers attributes of well-being that were found to be important to adults in the UK. It has five dimensions (attachment, stability, achievement, enjoyment and autonomy) and assesses broader well-being. Participants will complete ICEpop capability measure for adults (ICECAP-A) on True Colours at week 0, 12, 24, 36 and 48.

\section{Oxford CAPabilities questionnaire-Mental Health}

This is a validated mental health specific capability well-being scale with 16 items. $^{28}$ The items cover different domains of well-being (overall health, social and recreational activities, loss of sleep due to worry, friendship and support, having suitable accommodation, feeling safe, likelihood of discrimination and assault, freedom of personal and artistic expression, appreciation of nature, self-determination, and access to activities or employment), each scored on a 5-point Likert scale. Participants will complete Oxford CAPabilities questionnaire-Mental Health (OxCAP-MH) on True Colours at week 0, 12, 24, 36 and 48.

Health Economics Questionnaire (HEQ). The HEQ has specifically been developed for mental health economic evaluations and is now also complemented with a COVID-19-related module (https://zenodo.org/record/4559752). It measures health and social care resource use, medication, absenteeism from work and presenteeism as well as sociodemographic background information. Participants will complete this on True Colours at week $0,12,24,36$ and 48.

\section{Sample size}

At week 12, PAX-D considers a three-point difference on QIDS$\mathrm{SR}_{16}$ scores between pramipexole and placebo to be clinically important (with SD of the scores of 5.4 based on those observed in the CEQUEL trial ${ }^{29}$ and produces a standardised effect size of 0.56$)$. The sample size to test differences between groups at $90 \%$ power and at a type one error rate of $5 \%$ would be 68 per group (136 total), increasing with $20 \%$ drop-out to 170 total. To test a similar sized difference in reward sensitivity and to ensure that type one error for both the depression score and the reward sensitivity tests is 0.05 or below, the sample size calculation can be determined using an alpha of 0.025 . At an alpha of 0.025 and power of $90 \%$, the required sample size would be 81 per group. Allowing for an estimated 20\% lost to follow-up would then increase the sample size to 102 per group (204 total).

\section{Statistical methods}

The primary outcome (change in QIDS-SR16 between baseline and week 12) will be analysed using a generalised linear mixed 
model utilising data collected at each weekly time point from randomisation and including the baseline outcome and minimisation factors as fixed effects. The model will include a random intercept for each participant to account for the repeated measures on the same participant and an interaction term for the treatment by time interaction to allow the treatment effect to differ at each time point.

Continuous secondary outcomes will be analysed using generalised linear models. The dichotomous secondary outcomes will be analysed using a logistic mixed effects regression model. These analyses will include a fixed effects randomised group and baseline level of the QIDS-SR ${ }_{16}$, with participants and trial site accounted for as random effects. Minimisation variables will be included as explanatory factors in the models. Mediational analysis will test whether changes in reward sensitivity mediate the effect of pramipexole on depressive symptoms. Health economic data analysis will assess group differences in quality of life, wellbeing, and work performance using a cost-utility analysis.

The primary and efficacy-based secondary analyses will be performed using an intention-to-treat approach for all randomised participants. Analyses of the mechanistic secondary outcomes and health economic outcomes will be performed in the set of participants who have the data required for the specific analyses (ie, no imputation will be performed for these analyses). Acceptability analyses will be performed on a subgroup of participants and trial clinicians who provide separate consent for aspect of the trial.

The main health economic analysis will include: (1) a detailed patient-level cost analysis of health, social care and other broader societal costs for both the pramipexole and placebo arms of the trial and (2) an incremental within-trial economic evaluation comparing the pramipexole and placebo arms of the trial in terms of their costs and outcomes over the 48 -week trial follow-up period.

The primary health economic analysis will be a cost-utility analysis from a health and social care perspective where qualityadjusted life-years will be calculated using utility values from the EQ- 5D-5L. Secondary economic analyses using the ICECAP-A and the OxCAP-MH capability indices as outcome measures will be also carried out. Further analyses will estimate costeffectiveness from a societal perspective. All economic analyses will be on an intention-to-treat basis.

\section{DISCUSSION}

PAX-D aims to test the effectiveness of pramipexole as an add-on medication to antidepressant treatment for people with TRD. Pharmacological options for patients with TRD are currently limited. ${ }^{2}$ The PAX-D trial is therefore timely and has the potential to inform best practice for this group of hard-to-treat patients. Pramipexole is a selective dopamine agonist and may have the potential to target symptoms of low motivation and anhedonia which are not targeted by readily available serotoninergic antidepressants. Dopamine is known to play a role in reward-based and punishment-based learning. The design of the trial also allows investigation of the mechanistic effects of pramipexole on reward sensitivity and whether changes in reward sensitivity can predict response to treatment. Furthermore, the trial will examine the acceptance, tolerability and cost-effectiveness of pramipexole treatment, and results from this study will inform clinical practice. ${ }^{30}$

\section{Author affiliations}

'Department of Psychiatry, University of Oxford, Oxford, UK
${ }^{2}$ Department of Primary Care Health Sciences, University of Oxford Nuffield, Oxford, UK

${ }^{3}$ Brain Network Dynamics Unit, University of Oxford, Oxford, UK

${ }^{4}$ Oxford Health NHS Foundation Trust, Oxford, UK

${ }^{5}$ Translational and Clinical Research Institute, Newcastle University, Newcastle upon Tyne, UK

${ }^{6}$ Inpatient Services, Cumbria, Northumberland, Tyne and Wear NHS Mental Health Trust, Northumberland, UK

${ }^{7}$ Independent Researcher, Unknown, UK

${ }^{8}$ Centre for Affective Disorders, Department of Psychological Medicine, Institute of

Psychiatry, Psychology and Neuroscience, King's College London, Bristol, UK

${ }^{9}$ Bristol Medical School, Bristol Population Health Science Institute, University of Bristol, Bristol, UK

${ }^{10}$ Division of Psychiatry, Faculty of Brain Sciences, University College London, London, UK

${ }^{11}$ Department of Health Economics, Medical University of Vienna, Wien, Austria

Twitter Sheena Kristine Au-Yeung @sheenaTKD and Andrea Cipriani @And_ Cipriani

Acknowledgements This work was supported by the National Institute for Health Research (NIHR) Biomedical Research Centre, Oxford (grant BRC-1215-20005), and the NIHR Oxford cognitive health Clinical Research Facility. ACi is also supported by an NIHR Research Professorship (grant RP-2017-08-ST2-006) and by the NIHR Oxford and Thames Valley Applied Research Collaboration.

Contributors MB, JoG, PC, PJH, L-MY, AndC, JR and JS conceived the study. MB, JoG, JaG, MS, PJH, PC, L-MY, RB, FC, CjH, JR, M-JA, SW, FC, AndC, AntC, CjH, DK, GL, IS, JS contributed to the development of the study protocol. MB, JoG, SW, AntC, DK, $J E$, GL, JaG, SR, SKA-Y and CE led local study implementation in the participating sites. L-MY, MS provided statistical support for the study. IS leads the economic analysis for the study. SKA-Y drafted the initial version of the manuscript. All authors reviewed, revised and approved the final version of the manuscript.

Funding This study is funded by the NIHR Efficacy and Mechanism Evaluation Programme (16/127/17) and supported by the NIHR Oxford Health Biomedical Research Centre. The NIHR is not involved in the design of the study and collection, analysis, and interpretation of data and in writing the manuscript.

Disclaimer The views expressed are those of the authors and not necessarily those of the UK National Health Service, NIHR or the Department of Health and Social Care.

Competing interests $\mathrm{MB}$ has acted as a consultant for Janssen Research, P1vital and CHDR, owns shares in P1vital Products and was previously a paid employee of P1vital. JoG has research funding from NIHR and Westminster Foundation. M-JA is supported by the NIHR Oxford cognitive health Clinical Research Facility. SW has received honoraria for talks from Lundbeck. All other authors declare no conflict of interests.

\section{Patient consent for publication Not applicable.}

Ethics approval PAX-D was approved by NHS Health Research Authority South West-Central Bristol Research Ethics Committee (IRAS ID: 253702, REC reference 19/SW/0216). Protocol V.3.0 24/08/2021. Further information on informed consent, confidentiality and data management can be found in the supplemental materials.

Provenance and peer review Not commissioned; externally peer reviewed.

Data availability statement No data are available.

Supplemental material This content has been supplied by the author(s). It has not been vetted by BMJ Publishing Group Limited (BMJ) and may not have been peer-reviewed. Any opinions or recommendations discussed are solely those of the author(s) and are not endorsed by BMJ. BMJ disclaims all liability and responsibility arising from any reliance placed on the content. Where the content includes any translated material, BMJ does not warrant the accuracy and reliability of the translations (including but not limited to local regulations, clinical guidelines, terminology, drug names and drug dosages), and is not responsible for any error and/or omissions arising from translation and adaptation or otherwise.

Open access This is an open access article distributed in accordance with the Creative Commons Attribution 4.0 Unported (CC BY 4.0) license, which permits others to copy, redistribute, remix, transform and build upon this work for any purpose, provided the original work is properly cited, a link to the licence is given, and indication of whether changes were made. See: https://creativecommons.org/ licenses/by/4.0/.

\section{ORCID iDs}

Sheena Kristine Au-Yeung http://orcid.org/0000-0002-0516-4755

Mary-Jane Attenburrow http://orcid.org/0000-0002-1248-8248

Andrea Cipriani http://orcid.org/0000-0001-5179-8321

Judit Simon http://orcid.org/0000-0001-9279-8627 


\section{REFERENCES}

1 Malhi GS, Bell E, Bassett D, et al. The 2020 Royal Australian and New Zealand College of Psychiatrists clinical practice guidelines for mood disorders. Aust N Z J Psychiatry 2021;55:7-117.

2 Rush AJ, Trivedi MH, Wisniewski SR, et al. Acute and longer-term outcomes in depressed outpatients requiring one or several treatment steps: a STAR ${ }^{*} \mathrm{D}$ report. $A m$ J Psychiatry 2006;163:1905-17.

3 Zhou X, Ravindran AV, Qin B, et al. Comparative efficacy, acceptability, and tolerability of augmentation agents in treatment-resistant depression: systematic review and network meta-analysis. J Clin Psychiatry 2015;76:e487-98.

4 Tundo A, de Filippis R, De Crescenzo F. Pramipexole in the treatment of unipolar and bipolar depression. A systematic review and meta-analysis. Acta Psychiatr Scand 2019;140:116-25.

5 Cusin C, lovieno N, losifescu DV, et al. A randomized, double-blind, placebo-controlled trial of pramipexole augmentation in treatment-resistant major depressive disorder. J Clin Psychiatry 2013;74:e636-41.

6 Corrigan MH, Denahan AQ, Wright CE, et al. Comparison of pramipexole, fluoxetine, and placebo in patients with major depression. Depress Anxiety 2000;11:58-65.

7 Franco-Chaves JA, Mateus CF, Luckenbaugh DA, et al. Combining a dopamine agonist and selective serotonin reuptake inhibitor for the treatment of depression: a doubleblind, randomized pilot study. J Affect Disord 2013;149:319-25.

8 Zarate CA, Payne JL, Singh J, et al. Pramipexole for bipolar II depression: a placebocontrolled proof of concept study. Biol Psychiatry 2004;56:54-60.

9 Goldberg JF, Burdick KE, Endick CJ. Preliminary randomized, double-blind, placebocontrolled trial of pramipexole added to mood stabilizers for treatment-resistant bipolar depression. Am J Psychiatry 2004;161:564-6.

10 Fawcett J, Rush AJ, Vukelich J, et al. Clinical experience with high-dosage pramipexole in patients with treatment-resistant depressive episodes in unipolar and bipolar depression. Am J Psychiatry 2016;173:107-11.

11 Shelton RC, Tomarken AJ. Can recovery from depression be achieved? Psychiatr Serv 2001;52:1469-78.

12 Cools R. Role of dopamine in the motivational and cognitive control of behavior. Neuroscientist 2008; 14:381-95.

13 Cools R, Altamirano L, D'Esposito M. Reversal learning in Parkinson's disease depends on medication status and outcome valence. Neuropsychologia 2006;44:1663-73.

14 Burdick KE, Braga RJ, Gopin CB, et al. Dopaminergic influences on emotional decision making in euthymic bipolar patients. Neuropsychopharmacology 2014;39:274-82.

15 Azim L, Hindmarch P, Browne G, et al. Study protocol for a randomised placebocontrolled trial of pramipexole in addition to mood stabilisers for patients with treatment resistant bipolar depression (the PAX-BD study). BMC Psychiatry 2021;21:334.

16 Walsh AEL, Browning M, Drevets WC, et al. Dissociable temporal effects of bupropion on behavioural measures of emotional and reward processing in depression. Philos Trans R Soc Lond B Biol Sci 2018;373:20170030.

17 Goodday SM, Atkinson L, Goodwin G, et al. The true colours remote symptom monitoring system: a decade of evolution. J Med Internet Res 2020;22:e15188.

18 Rush AJ, Trivedi MH, Ibrahim HM, et al. The 16-Item quick inventory of depressive symptomatology (QIDS), clinician rating (QIDS-C), and self-report (QIDS-SR): a psychometric evaluation in patients with chronic major depression. Biol Psychiatry 2003;54:573-83.

19 Altman EG, Hedeker D, Peterson JL, et al. The Altman self-rating mania scale. Biol Psychiatry 1997;42:948-55.

20 Spitzer RL, Kroenke K, Williams JBW, et al. A brief measure for assessing generalized anxiety disorder: the GAD-7. Arch Intern Med 2006;166:1092.

21 Snaith RP, Hamilton M, Morley S, et al. A scale for the assessment of hedonic tone the Snaith-Hamilton Pleasure scale. Br J Psychiatry 1995;167:99-103.

22 Hughes ME, Waite LJ, Hawkley LC, et al. A short scale for measuring loneliness in large surveys: results from two population-based studies. Res Aging 2004;26:655-72.

23 Steptoe A, Breeze E, Banks J, et al. Cohort profile: the English longitudinal study of ageing. Int J Epidemiol 2013;42:1640-8.

24 Bharmal M, Payne K, Atkinson MJ, et al. Validation of an abbreviated treatment satisfaction questionnaire for medication (TSQM-9) among patients on antihypertensive medications. Health Qual Life Outcomes 2009;7:36.

25 Weintraub D, Mamikonyan E, Papay K, et al. Questionnaire for Impulsive-Compulsive disorders in Parkinson's Disease-Rating scale. Mov Disord 2012;27:242-7.

26 Mundt JC, Marks IM, Shear MK, et al. The work and social adjustment scale: a simple measure of impairment in functioning. Br J Psychiatry 2002;180:461-4.

27 Al-Janabi H, Flynn TN, Coast J. Development of a self-report measure of capability wellbeing for adults: the ICECAP-A. Qual Life Res 2012;21:167-76.

28 Vergunst $F$, Jenkinson C, Burns T, et al. Psychometric validation of a multi-dimensional capability instrument for outcome measurement in mental health research (OxCAPMH). Health Qual Life Outcomes 2017;15:250.

29 Geddes JR, Gardiner A, Rendell J, et al. Comparative evaluation of quetiapine plus lamotrigine combination versus quetiapine monotherapy (and folic acid versus placebo) in bipolar depression (CEQUEL): a $2 \times 2$ factorial randomised trial. Lancet Psychiatry 2016:3:31-9.

30 Vancak V, Goldberg Y, Levine SZ. Guidelines to understand and compute the number needed to treat. Evid Based Ment Health 2021:24:131-6. 